\title{
Patient-Reported Difference following Implantation of a Blue Light-Filtering Aspheric Intraocular Lens and a UV-Filtering Aspheric Intraocular Lens
}

\author{
Cédric Schweitzer Joseph Colin ${ }^{+}$ \\ Department of Ophthalmology, University Hospital Pellegrin, Bordeaux, France
}

\section{Key Words}

Blue-blocking intraocular lens · UV filter · Visual quality · Yellow vision

\begin{abstract}
We report on a series of 6 patients who experienced yellow vision after uncomplicated cataract surgery in their second eye. In the first eye, an aspheric blue-light filtering intraocular lens (IOL) was implanted, followed by the implantation of a 1-Piece aspheric IOL in the second eye. The time between the surgeries ranged from 12 months to 3 years. The patients experienced noticeable differences between the yellow and the clear lens. It is suggested to avoid mixing blue light-filtering and UV-filtering IOLs in the same patient, particularly in those who have high expectations following cataract surgery.
\end{abstract}

(C) 2013 S. Karger AG, Basel

\section{Introduction}

The introduction of blue light-filtering intraocular lenses (IOLs) was intended to provide protection against light-induced retinal damage, along with the development or progression of age-related macular degeneration. Although they are widely used today, these lenses have supporters and detractors [1-8]. In a review article by Cuthberston et al. [5] from 2009, the authors noted that 'convincing epidemiologic evidence for humans is sparse'. Further, a study by the Macular Pigment Research Group [6] reported that while blue light-filtering IOLs were associated with an augmentation in macular pigment optical density, it could not 
Colin et al.: Patient-Reported Difference following Implantation of a Blue LightFiltering Aspheric Intraocular Lens and a UV-Filtering Aspheric Intraocular Lens

be determined whether these IOLs were associated with a reduced risk of age-related macular degeneration. On the other hand, recent studies have demonstrated the benefit of blue light-filtering IOLs in reducing light-induced retinal pigment epithelium damage $[7,8]$.

One of the questions surrounding these lenses has been whether this change in color blocking has an effect on the patient's vision, with initial studies demonstrating no difference in color perception in patients undergoing implantation of these lenses [2, 9].

\section{Materials and Methods}

In the cases reported here, the patients received a blue light-filtering IOL (AcrySof IQ Natural SN60WF; Alcon Laboratories, Fort Worth, Tex., USA) in their first operated eye followed by implantation of a non-blue light-filtering IOL in their second eye (Tecnis 1-Piece IOL; Abbott Medical Optics, Santa Ana, Calif., USA). The AcrySof IQ is a 1-piece, hydrophobic acrylic IOL with UV and blue light-filtering chromophores. The lens has a 6-mm aspheric optic with an overall length of $13 \mathrm{~mm}$ [10]. The Tecnis 1-Piece IOL is a hydrophobic acrylic IOL with a UV filter. This lens also has a 6-mm aspheric optic with an overall length of $13 \mathrm{~mm}$ [11]. Both IOL models were implanted with an injector via a clear cornea incision of $2.8 \mathrm{~mm}$.

Preoperative, surgical and postoperative patient care as well as the examinations followed the standard protocol for cataract patients at the clinic. The patients were seen 6 months following surgery.

SPSS statistics software package version 15.0.1 for Windows (IBM, Armonk, N.Y., USA) was used for statistical analysis. The Mann Whitney $U$ test was applied to assess the significance of differences, using the same level of significance $(\mathrm{p}<0.05)$ in all cases.

\section{Results}

The time between cataract surgery in the first and surgery in the second eye ranged from 12 months to 3 years, with a mean of 22.5 months. None of the patients had undergone a posterior Nd:YAG capsulotomy prior to cataract surgery in the second eye. Table 1 summarizes the age, gender and sequence of implantation as well as uncorrected distance and corrected distance visual acuity (UCVA and CDVA) at 6 months after surgery.

Although the mean UCVA and CDVA were slightly better in the Tecnis eyes (UCVA = 0.75 ; CDVA $=0.95$ ) compared to the SN60WF eyes (UCVA $=0.65$; CDVA $=0.87$ ), this was not statistically significant due to the small number of eyes (UCVA $p=0.47$; CDVA $p=0.26$ ).

\section{Discussion}

There is ongoing controversial discussion about the impact of blue light-filtering IOLs on visual quality. In a randomized, double-masked clinical study of 48 eyes (24 patients) implanted with a blue light-filtering IOL in one eye and a UV-filtering IOL in the other, investigators found that the blue light-filtering IOLs had a negative impact on contrast acuity as well as blue/yellow foveal threshold compared to the outcomes seen in the UV-filtering IOLs. In addition, 3 of the patients reported a difference in visual impression between the two eyes [12]. Another study assessed color discrimination between patients implanted with blue light-filtering IOLs (15 with photochromic and 13 with yellow-tinted IOLs) and 15 subjects implanted with UV-filtering IOLs. Additionally, the patients were given the National 
Colin et al.: Patient-Reported Difference following Implantation of a Blue LightFiltering Aspheric Intraocular Lens and a UV-Filtering Aspheric Intraocular Lens

Eye Institute Visual Functioning Questionnaire (NEI VFQ-25). This study found that under mesopic conditions, there was a statistically significant difference in partial error scores in the green to blue-green color band. However, there was no statistically significant difference under photopic conditions or in the questionnaire results [13]. A Swiss study comparing patient color perception and contrast sensitivity found that there was no difference in eyes implanted with a conventional UV-filtering IOL (AcrySof SA60AT; Alcon) and a blue lightfiltering IOL (AcrySof SN60AT) in terms of color testing and contrast sensitivity. However, of the 23 patients (46 eyes), 4 (17.4\%) reported a difference in monocular color perception and $5(21.7 \%)$ noticed a difference in contrast sensitivity between the two eyes [14].

In the study by Cionni and Tsai [2], the color perception of patients with bilateral blueblocking IOLs was compared to the color perception of those implanted with bilateral UVblocking IOLs as well as to a phakic group using the Farnsworth-Munsell 100-hue test. This study showed no difference in the color perception between the various groups.

From the cases reported here, 6 patients reported a distinct difference between the vision with the blue light-filtering IOL and that with the UV-filtering IOL, although all eyes achieved good UCVAs and CDVAs. The patients were satisfied with their vision after the initial surgery with the SN60WF, but all 6 reported a sudden impression of yellow vision in the first eye following implantation of the Tecnis lens in the other eye. No additional testing was performed to clinically quantify the patients' subjective findings because previous studies have shown that color vision testing results are not modified in patients implanted with a blue light-filtering IOL. Although the 6 patients complained about their vision, none requested explantation of the SN60WF.

The results suggest that given the noticeable difference experienced by the patients, it is best to avoid mixing blue light-filtering and UV-filtering IOLs in the same patient, particularly in those who have high expectations following cataract surgery.

\section{References}

$\checkmark 1$ Leibovitch I, Lai T, Porter N, Pietris G, et al: Visual outcomes with the yellow intraocular lens. Acta Ophthalmol Scand 2006;84:95-99.

-2 Cionni RJ, Tsai JH: Color perception with the AcrySof natural and AcrySof single-piece intraocular lenses under photopic and mesopic conditions. J Cataract Refract Surg 2006;32:236-242.

-3 Wohlfart C, Tschuschnig K, Fellner C, Boci K, et al: Visual function with blue light filtering IOLs. Klin Monbl Augenheilkd 2007;224:23-27.

-4 Mester U, Holz F, Kohnen T, Lohmann C, Tetz M: Intraindividual comparison of a blue-light filter on visual function: AF-1 (UY) versus AF-1 (UV) intraocular lenses. J Cataract Refract Surg 2008;34:609-615.

5 Cuthberston FM, Peirson SN, Wulff K, Foster RG, et al: Blue light-filtering intraocular lenses: review of potential benefits and side effects. J Cataract Refract Surg 2009;35:1281-1297.

-6 Nolan JM, O’Reilly P, Loughman J, Stack J, et al: Augmentation of macular pigment following implantation of blue light-filtering intraocular lenses at the time of cataract surgery. Invest Ophthalmol Vis Sci 2009;50:4777-4785.

$\checkmark 7$ Kernt M, Himeiss C, Neubauer AS, Lackerbauer CA, et al: Protective effect of blue light-absorbing IOLs on the human retinal pigment epithelium. Ophthalmologe 2010;107:150-157.

-8 Patel S, Dacey DM: Relative effectiveness of a blue light-filtering intraocular lens for photoentrainment of the circadian rhythm. J Cataract Refract Surg 2009;35:529-539.

-9 Ernest PH: Light-transmission-spectrum comparison of foldable intraocular lenses. J Cataract Refract Surg 2004;30:1755-1758.

10 AcrySof IQ Package Insert. Alcon Laboratories, Fort Worth, Tex.

11 Tecnis 1-Piece Package Insert. Abbott Medical Optics, Santa Ana, Calif.

12 Wirtitsch MD, Schmidinger G, Prskavec M, Rubey M, et al: Influence of blue-light-filtering intraocular lenses on color perception and contrast acuity. Ophthalmology 2009;116:39-45.

13 Ao M, Chen X, Huang C, Li X, et al: Color discrimination by patients with different types of light-filtering intraocular lenses. J Cataract Refract Surg 2010;36:389-395.

14 Eberhard R, Roberti P, Prünte C: Intraindividual comparison of color perception and contrast sensitivity with and without a blue light-filtering intraocular lens. Eur J Ophthalmol 2009;19:235-239. 
Colin et al:: Patient-Reported Difference following Implantation of a Blue Light Filtering Aspheric Intraocular Lens and a UV-Filtering Aspheric Intraocular Lens

Table 1. Age, gender, sequence of implantation as well as UCVA and CDVA in our case series (OD = oculus dexter; OS = oculus sinister)

\begin{tabular}{|c|c|c|c|c|c|c|c|c|c|c|}
\hline \multirow[t]{2}{*}{ Case } & \multirow[t]{2}{*}{ Age } & \multirow{2}{*}{$\begin{array}{l}\text { Gen- } \\
\text { der }\end{array}$} & \multicolumn{4}{|c|}{ AcrySof SN60WF } & \multicolumn{4}{|c|}{ Tecnis 1-Piece IOL } \\
\hline & & & $\begin{array}{l}\text { IOL } \\
\text { power }\end{array}$ & $\begin{array}{l}\text { Date of } \\
\text { surgery }\end{array}$ & UCVA & CDVA & IOL power & $\begin{array}{l}\text { Date of } \\
\text { surgery }\end{array}$ & UCVA & CDVA \\
\hline 1 & 62 & M & 22.5 OD & $11 / 2006$ & 0.6 & 1.0 & $22.0 \mathrm{OS}$ & $11 / 2008$ & 0.7 & 1.0 \\
\hline 2 & 75 & M & $19.0 \mathrm{OS}$ & $9 / 2005$ & 0.4 & 0.7 & 20.0 OD & $11 / 2008$ & 0.6 & 0.9 \\
\hline 3 & 67 & $\mathrm{~F}$ & $24.0 \mathrm{OD}$ & $2 / 2007$ & 0.8 & 0.9 & 24.5 OS & $12 / 2008$ & 0.9 & 1.0 \\
\hline 4 & 83 & $\mathrm{~F}$ & $22.0 \mathrm{OD}$ & $1 / 2008$ & 0.7 & 1.0 & 23.5 OS & $1 / 2009$ & 1.0 & 1.0 \\
\hline 5 & 74 & $\mathrm{~F}$ & 21.5 OS & $6 / 2007$ & 0.6 & 0.8 & $22.0 \mathrm{OD}$ & $12 / 2008$ & 0.7 & 0.8 \\
\hline 6 & 72 & M & $24.5 \mathrm{OD}$ & $2 / 2006$ & 0.8 & 0.8 & $25.0 \mathrm{OS}$ & $11 / 2008$ & 0.6 & 1.0 \\
\hline
\end{tabular}

